\title{
AZAR Y PSICOANÁLISIS: UNA INTERPRETACIÓN DEL SUEÑO EN NADIE NADA NUNCA DE JUAN JOSÉ SAER
}

\author{
François Degrande \\ Universidad Católica de Lovaina (Bélgica) \\ francoisdegrande@hotmail.com
}

RESUMEN / ABSTRACT

Frente a las lecturas de orientación psicoanalítica (Premat, Corbatta), otro modo de leer a Saer tiende a resaltar el peso innegable del azar en su obra (Dalmaroni y Merbilhaá, Iglesia). Nuestra lectura intenta esclarecer la maniobra narrativa de Saer al orquestar el improbable matrimonio del azar con el psicoanálisis en Nadie nada nunca. Siguiendo a Baudrillard en Las estrategias fatales, el psicoanálisis tendió a "eliminar el azar de los lapsus, de los actos fallidos, de los sueños, de la locura"(162). Si la reunión de la causalidad y de la casualidad es problemática en la quinta novela de Saer, sostenemos que esta situación se debe al terror dictatorial. Para intentar probar esto, el trabajo ahonda en el sueño del Gato (cap. II) que se desarrolla en un casino-prostíbulo. Este episodio - mise en abyme fundamental de la novelanos permite adentrarnos en la alegorización de lo arbitrario dictatorial y es la ocasión de resaltar la maestría de Saer cuando instrumentaliza las colusiones de intereses azarosos y psicoanalíticos en una base económica cuestionable.

PALABRAS ClAVE: Saer, literatura argentina, psicoanálisis, sueño, azar.

In contrast with psychoanalytic readings (Premat, Corbatta), another way of reading Saer highlights the relevance of chance in his work (Dalmaroni and Merbilhaá, Iglesia). Both types of readings pose theoretical questions. Indeed, as Baudrillard puts it in Les stratégies fatales, "psychoanalysis [...] and its unconscious interpretation have ruled out the accidental nature of lapsus, of Freudian slips, of dreams, of madness (162)"'. Our reading attempts to shed light on the literary project of the Argentinian writer as he plots the improbable relation of 
chance and psychoanalysis in his fifth novel, Nadie nada nunca. In this vein, the problematic coexistence of causality and chance can only be explained by the dictatorial terror that permeates this novel. To prove this, the article analyzes the oneiric world of El Gato (II), in which the freudian principle of condensation turns a bawdy house into a casino. This crucial episode -mise en abyme of the novel-leads us into the allegorization of the dictatorial arbitrary, and enables us to regard Saer's literary achievement as he instrumentalizes the random and psychoanalytic collusions of interests in semiotic games.

KEY WORDS: Saer, argentinian literature, psychoanalysis, dream, chance.

La narrativa del escritor argentino Juan José Saer (Santa Fe 1937- París 2005), por el fondo pulsional que acarrea es frecuentemente objeto de estudios de raigambre psicoanalítica. Pensamos en especialistas como Premat en el ingente trabajo La dicha de Saturno. Escritura y melancolía en la obra de Juan José Saer (2002) o en Corbatta (2005), autora de Juan José Saer, Arte poética y práctica literaria. En ciertos aspectos, Saer se presta bien a esta orientación crítica: el duelo, la melancolía, la violencia, la locura, el sueño, la adicción al juego, son rastreables en su narrativa. Si el escritor se empapó cuidadosamente de las tesis freudianas que no dejó de reescribir (Premat, $L a$ dicha de Saturno), hace falta ver que otras lógicas, menos exploradas por la crítica, subyacen en su obra.

De hecho, frente a las lecturas de orientación psicoanalítica, otro modo de leer a Saer tiende a resaltar el peso innegable del juego y del azar en su obra. $\mathrm{Al}$ respecto, una serie de títulos en la literatura secundaria son elocuentes: "Un azar convertido en don. Juan José Saer y el relato de la percepción" (Dalmaroni y Merbilhaá), La violencia del azar. Ensayo sobre literatura argentina (Iglesia) o "Cicatrices de Juan José Saer: el peligroso juego de la literatura" (Panesi). Si esta faceta de su arte caracteriza todo su ciclo novelesco, desde La vuelta completa (1961-1963) hasta La grande (2005)2, es preciso ver que culmina en Cicatrices (1969), obra en la que la atracción por el azar alcanza sus efectos más devastadores. Al convocar movimientos aleatorios e incontrolables como modo de explicar cierta vertiente violenta

\footnotetext{
J. Premat señala a propósito de La grande: "Sin embargo, y antes de continuar me parece importante acotar que el título también incluye, por supuesto, una distancia burlona (la referencia a la lotería, a un 'sacarse la grande') ironía que impone cierta prudencia a la hora de juzgar el aparente clasicismo del texto o su ambientación panorámica" (Premat, "Saer, nota y sinfonía" 270 ).
} 
de la obra de Saer -con apuestas políticas contundentes-, parte de la crítica analiza la casualidad, lo fortuito, la violencia arbitraria, incluso, pero con la meta de conceder a estos rasgos siempre difíciles de interpretar un sentido y una interpretación convincentes, lo cual se acerca a un método explicativo afín a la práctica psicoanalítica, aunque menos asumido.

Como se ve, las obras de Saer dan pie a una pluralidad de lecturas. En el marco de este estudio, nos pareció fructífero volver a comentar Nadie nada nunca (1980), un texto sumamente polisémico. Ante tendencias interpretativas disímiles nació el proyecto de adentrarnos en una lectura que se sirviera "razonablemente" del psicoanálisis y del azar, procurando ver lo que se pierde al "explicar" la casualidad o al buscar el punto ciego de una causalidad pasada desapercibida. Nuestra reflexión se nutrió del pensamiento de Baudrillard, quien observó en Las estrategias fatales que el psicoanálisis tendió a "eliminar el azar de los lapsus, de los actos fallidos, de los sueños, de la locura"',(162). Claro está que la perspectiva de sentirse desnudo frente al azar hostiga necesariamente a cualquier crítico psicoanalista, ya que representa a largo plazo su ruina potencial. La interpretación del azar interroga pues el hecho de que pueda existir allí también, más que en cualquier otro fenómeno, una "causa escondida", lo cual siempre es estimulante en la investigación en las ciencias humanas, como subrayó Morin en La rumeur d'Orléans: "La investigación de una causa escondida para rendir cuenta de caracteres constitutivos de una realidad es el proceso mismo de la investigación científica"(148).

Más concretamente, en el marco de este trabajo, nuestro punto de partida será el sueño del Gato Garay en el capítulo II de Nadie nada nunca. Como veremos, este episodio interroga los resortes aleatorios de la forma lúdica en una atmósfera onírica, de ahí que convenga esclarecer el retorno del azar en el psicoanálisis, rasgo de escritura especialmente digno de interés en Saer.

\section{FUNCIÓN DEL SUEÑO DEL GATO}

Antes que nada, creemos de interés situar el episodio onírico en la diégesis de esta novela que escenifica de modo indirecto la tortura asociada a las realidades extraliterarias de la dictadura militar argentina (1976-1983). Como 
bien es sabido, la historia transcurre a orillas del Paraná, en febrero, o sea en pleno verano argentino. Un serial killer mata a caballos y siembra el pánico. El personaje principal, el Gato Garay, pasa tres días en su casa en la costa (Rincón) para cuidar de un bayo que le ha confiado Don Layo. Este último cree que el caballo estará más al amparo de la violencia de la cual son víctimas los caballos, allí, lejos de las tensiones y de los peligros de la ciudad. Durante estos tres días, el Gato mantiene su relación amorosa con su querida, Elisa. Esta le trae un libro de Sade, mandado desde Francia, por Pichón Garay, su hermano. El Gato recibe otras visitas, inclusive la de Tomatis el domingo quien le trae noticias a propósito de la situación en la ciudad. Para resolver el enigma planteado por el matador múltiple, el comisario, Caballo Leyva, hace varias detenciones, pero no consigue detener al culpable. Caballo morirá también. Los asesinatos de caballos se multiplican y llegan a alcanzar el paroxismo de la crueldad. Bien podría ser que el culpable fuera el mismo Gato ya que una pistola se encuentra en su entorno. Al final del libro, el lector no sabe bien quién es el autor de los asesinatos y si el libro tiende falsamente hacia la idea de Génesis (la frase inicial no deja de repetirse "No hay, al principio, nada. Nada".) es de observar que fuertes señales apocalípticas caracterizan la obra.

Muy pronto en esta novela oscura, en el capítulo segundo (23-30), el lector se inmiscuye en el sueño del Gato, se trata de uno de los lugares más impactantes de la novela. En este sueño sucede una partida de juego. Estamos inmersos en un casino, como sucede a menudo en Saer (Responso, Cicatrices):

En la puerta de la casa de juego - que está bastante oscura- me encuentro con Elisa. Tomatis le ha dado la dirección. Elisa quiere impedirme entrar porque tiene el presentimiento de que voy a perder. Me recomienda sobre todo que no juegue el número tres (27-28).

Yo me hago notar que su recomendación es ambigua: ¿ me está queriendo decir que no juegue el número tres, como si yo tuviese un número tres para perder, alguna cosa designada con el número tres, o bien que no juegue al número tres, es decir que no haga ninguna apuesta a ese número?

“¿Te da miedo que me quede sin número tres?”, le digo, malicioso, sin dejarle entender que estoy pensando en que Freud designa con el número tres los órganos genitales, y después, poniéndole la mano en la vagina por encima del vestido sedoso que lleva puesto, le digo, riendo: "el número tres es para el bosquecito" (28).

Por fin entramos juntos en la casa de juego que, como puede percibirse de inmediato, es también prostíbulo (28). 
A pesar de la comicidad aparente de este fragmento, debemos señalar que por el ambiente general de este apartado onírico, no sería erróneo asociarlo a la pesadilla, sobre todo si se tiene en cuenta la etimología del término "nightmare" del inglés, como puntualizó Borges: "Hay un tipo de sueño que merece nuestra singular atención. Me refiero a la pesadilla, que lleva en inglés el nombre de nightmare o yegua de la noche, voz que sugirió a Victor Hugo la metáfora de cheval noir de la nuit, pero que, según los etimólogos, equivale a ficción o fábula de la noche" (Borges, Libro de sueños 8$)^{4}$. Sea lo que fuere, el sueño o la pesadilla del Gato, parece remitir al procedimiento narrativo de la prolepsis. Sería tentador incurrir en una lectura en primer grado del sueño del Gato y un análisis de este episodio nos llevaría pues a lo siguiente: El Gato encierra un inconsciente muy marcado por los caballos y la violencia; puede ser que por este motivo sea él el asesino. A nivel intratextual, este sueño está asociado a fragmentos significativos por lo que no se puede rehusar su utilidad durante el acto de lectura. Cuando se termina el libro, el lector hasta tiene la impresión de que su función era la de colmar de entrada una ausencia de descripción en la presentación del Gato. Ya se entrevén, por otro lado, las obsesiones ${ }^{5}$ que hostigan al Gato por la mera realización de este sueño. En efecto, si hacemos caso del principio freudiano que pretende que el sueño viene a revelar después de un trauma la parte inconsciente de uno y que ésta engloba los acontecimientos pasados durante el estado de vigilia, bien se puede considerar que el día antes el protagonista vivía una experiencia fuerte y vecina a la muerte. Mirándolo bien, todo sucede como si el brote de lo inconsciente en este sueño materializase la repetición y la obsesión de los asesinatos en el marco de ciertas pulsiones de juego.

Sin embargo, según creemos, el sueño no es una asimilación onírica de los acontecimientos de un antes que el lector desconoce, en todo caso, sino más bien una síntesis preocupante de otros hechos que suceden en el tiempo

$4 \quad$ Borges prosigue: “Alp, su nombre alemán, alude al elfo o íncubo que oprime al soñador y que le impone horrendas imágenes. Ephialtes, que es el término griego, procede de una superstición análoga" (Borges, Libro de sueños 8). La asociación del caballo y del sueño llamó la atención de Borges en otras ocasiones: ver Groussac, Paul. "Entre sueños" en Borges, (Libro de sueños 177-178). Igualmente podríamos mencionar la asociación entre el sueño y el caballo, desde un plan premonitorio, en El astillero de Onetti (171).

"Una novela es siempre la historia de la obsesión de un personaje" (Piglia, "El lugar de Saer" 177). 
de la narración a este sueño ${ }^{6}$. Es, al fin y al cabo, un rodeo metafórico y proléptico que "condensa" (Freud 320-346) un prostíbulo y un barco y que "desplaza" (Freud 346-351) el universo dictatorial en el microcosmo de un casino; aquí es tentador recordar los famosos buques-casinos en Puerto Madero de Buenos Aires, hábilmente situados para evitar la ley que impide la presencia de casinos en la tierra firme porteña. En cuanto a la asociación casino-prostíbulo remite a una condensación peculiar, reanudando con la historia ya que al principio, el término "casino" igualmente designaba a las casas de prostitución ${ }^{7}$.

Como podemos observar, la presencia de Freud $^{8}-$ ¿como significante?en el fragmento citado se halla cargada de una señal de superstición, ya que el psicoanalista austriaco de pronto surge en la sintaxis onírica en el puente movedizo entre azar e interpretación de los sueños. La cita de Saer traiciona un fondo inconsciente que no se ignora del todo ya que, como acabamos de leer: "Freud designa con el número tres los órganos genitales" (28). La oración aparece dentro de un sueño que actúa como una especie de profecía onírica9; en realidad, de modo general, el sueño da la impresión de que todo ha sido dicho, ya en las alturas primerizas de la novela. La premonición en la doble dimensión de "presentimiento y de presagio" (DRAE) es algo que, dicho sea de paso, permite decir, que no obró el azar, dado que las cosas

$6 \quad$ Cierto es que a continuación el libro no hace sino regresar sobre elementos que aparecían en el sueño: "Sequía y caballos es lo único de lo que se habla en el mercado. Pero el gran recinto que ocupa toda una manzana está menos animado que de costumbre, y menos concurrido. Algunos puestos están cerrados. La carne cruda cuelga de los ganchos por sobre los mostradores de las carnicerías. Se ven riñones, corazones, tripas que penden en ovillo. Sobre el mármol de los mostradores pueden verse, acomodados de a pares, testículos de toro" (156).

Ver Le Trésor de la langue française informatisé. Información disponible en la página http://atilf.atilf.fr/dendien/scripts/tlfiv5/advanced.exe?8;s=3108399000; y consultada el 8 de febrero de 2013.

“[...] Stekel igualmente ha atribuido a los nombres que aparecen a menudo en los sueños significaciones simbólicas fijas, pero estas soluciones no aparecen ni lo suficientemente establecidas con certidumbre ni universalmente válidas, aun si en los casos individuales la interpretación puede ser reconocida lo más frecuentemente como verosímil. [...] El número tres es por lo demás un símbolo del órgano genital masculino establecido de distintos lados; una de las generalizaciones instituidas por Stekel hace referencia a la significación doble de los símbolos genitales" (Freud 399).

9 Como sucede en el sueño de El astillero, la profecía onírica igualmente impera en Cicatrices: la hija de Fiore había soñado la escena de caza. 
se manifestaron en sueños, signos o cifras, por anticipado. Cierto es que el humorismo de Saer da en el blanco: el retorno del azar en pleno corazón del psicoanálisis puede ser aparentado a un juego tramposo urdido en contra de Freud a no ser que sea más bien un brote psicoanalítico despertado involuntariamente por el azar. De hecho, el humor en Nadie nada nunca está para probar que, a lo mejor, el psicoanálisis no debe dejar de concebirse como un juego, así como lo era al principio, como señala Winnicott en Realidad y juego: "El juego puede ser una forma de comunicación en psicoterapia y, en último lugar, diría que el psicoanálisis se desarrolló como una forma muy especializada del juego puesta al servicio de la comunicación consigo mismo y con los demás" $(60)^{10}$. Ni que decir que la clave cómica cuyo soporte es la combinación azar y psicoanálisis ofrece cierto alivio al lector inmerso en el contexto horroroso de la dictadura militar.

Queriendo afinar nuestro propósito, es necesario esclarecer cómo la escritura se las arregla para albergar los albures del matrimonio entre azar y psicoanálisis en Nadie nada nunca. Se desvela elocuente parte de la maniobra del autor: Saer hace de Freud un tema soñado digno de una interpretación freudiana y la astucia se halla reforzada por lo que la preocupación freudiana por antonomasia -la sexualidad-se evoca en torno a la cifra "tres", espejo psicoanalítico y apuesta denegada que también se asocia al triángulo adúltero de la historia y al número de días (3) en los que transcurre la diégesis que cubre esta misma relación. El guiño de Saer a los consumidores de Freud equivale, en cierto modo, a sugerir que el mismo Freud, en tanto que tema soñado, es digno de figurar en un diccionario de interpretación de los sueños, valga el posible ataque de Saer al psicoanálisis o a su perdición en los descensos tragicómicos de la mise en abyme ${ }^{11}$.

10 Si sostenemos que el tratamiento de la materia psicoanalítica es innovador en Saer, podemos contrastar su humorismo con el estilo "menos ambiguo" de Puig: "Antes se interpretaba que el inconsciente era como una bolsa de gatos, donde todo cae y se mezcla". [...] "El inconsciente no es una memoria de donde se pueden sacar las fichas como de un archivo. Hay un modelo de funcionamiento, pero que no puede ser captado concretamente, sino a través de la ficción del lenguaje" (Puig, Pubis angelical 138). Bastaría igualmente con pensar en la cripta de El beso de la mujer araña -las notas a pie de páginas- para pensar entonces en la seriedad del juego psicoanalítico en el caso de Puig, cuando en Saer, lo que se da es más bien el juego en torno a la seriedad psicoanalítica.

11 Ricardou asevera a propósito de la mise en abyme: "Determinar una mise en abyme en semejante dispositivo, es descubrir una secuencia que pueda cumplir con dos condiciones: por una parte, hacer prueba de una cohesión suficiente para alcanzar, de hecho, a pesar de 
Como podemos apreciar, este fragmento nos enseña una combinación llamativa entre azar y psicoanálisis a partir del valor de la cifra tres. ¿Es el juego solo aparentemente gratuito? Para contestar esta pregunta, conviene obrar con máxima prudencia. Puede que el episodio en cuestión no constituya más que una estrategia por parte de Saer para precipitar al lector hacia errores interpretativos. En otros términos, es posible que Freud en el abismo del sueño reenvíe falazmente a una trampa para "dictar" una lectura psicoanalítica de la obra. A estas alturas del análisis, conviene recordar la cautela de Saer: no le faltó nunca la agudeza crítica y no dudó en criticar los abusos de ciertos tipos de lectura empapados de psicoanálisis "escolarmente aplicado". Lo puntualiza Giordano en "El efecto de irreal": "Agrego, a modo de suplemento, una perífrasis de la lectura que realiza Saer de Tierras de la memoria de Felisberto Hernández. [...] Saer abre su interpretación polemizando con una modalidad de la exégesis realista: el psicoanálisis (escolarmente) aplicado. El primer gesto es de advertencia: se trata de no "caer en la trampa" (34).

Acabamos de sugerir la presencia significativa de una mise en abyme por lo que el ambiente del juego tiene que ver con el que se encuentra en la novela en general. Basándonos en Le nouveau roman de Ricardou podríamos detectar en el sueño del Gato un "relato satélite":

En la medida en que el relato-satélite, para hablar como Hugo, resume el gran relato que contiene, desempeña el papel de un revelador. Por una parte de modo general (repetición); por otra parte, según rasgos distintivos (condensación, anticipación). Repetición: toda mise en abyme multiplica por lo que imita o, si se prefiere, subraya volviendo a decir. Condensación: pero vuelve a decir de otra manera; la mayoría de las veces, pone en juego acontecimientos muy simples, muy breves; en esta condensación, los dispositivos repercutidos tienden a tomar una nitidez esquemática. Anticipación: además, sucede a menudo que los micro-acontecimientos que la mise en abyme encubre preceden los macro-acontecimientos correspondientes ; en este caso, la revelación corre el riesgo de estar tan activa que todo el relato pueda pasar por alto (50).

La repetición, la condensación, la anticipación vienen programadas en este sueño y son irrebatibles los indicios que apuntan a la mise en abyme. Podemos

la fragmentación, una localización suficientemente firme; por otra parte, reunir una cantidad convincente de analogías con tales aspectos irrecusables del libro" (Ricardou 65). 
pensar en los colores: la importancia de lo negro caracteriza el sueño y toda la novela. Es igualmente legítimo evocar la deserción de la especie humana que alude al malestar dictatorial y que se refleja en la novela entera: "En la sala de juego, no hay casi nadie: todavía no han empezado" [...] "Tengo la impresión de estar en la única sala iluminada de una gran construcción oscura" (29). Otros detalles igualmente nos muestran que juego y dictadura se sitúan en el mismo nivel en este sueño. En efecto, en la siguiente oración es especialmente revelador el tipo de saludo hecho: "El empleado hace una especie de saludo militar, con la bolita de la ruleta en la mano, y dice: 'Partida"' (29). Como subrayó Sarlo, el sueño es una clave de lectura fundamental: "Pero el sueño (cifra de todo el texto) queda diferido hasta que finalmente volverá el Gato, sudado, a pararse en la oscuridad, junto a su cama recién salido del sueño, que ahora sí hemos leído" (Sarlo 283). Sigamos ahondando en el contenido de este sueño tan llamativo.

\section{ELCASINO-PROSTÍBULO: VARIACIONES EN TORNO A LA MONEDA}

Comencemos por señalar que la regresión del hombre que caracteriza toda la novela $-y$ que refleja las realidades extraliterarias- se halla materializada en la curiosa regresión de los sistemas de signos dentro del casino soñado. Todo esto parece tener que ver con el sistema del horror narrado: son dos caras de una moneda peligrosa de la cual se adueña la narración saeriana. Por eso, la escritura de la tortura en Nadie nada nunca nos induce a pensar que puede resultar interesante transitar por la pista monetaria, ya que por sus dos caras, la moneda se convierte en el nexo de unión entre regresión y caos al poder apreciarse como un espejo de la Argentina de la guerra sucia.

Veamos pues lo que se esconde detrás de la carne como significante en el casino-prostítublo, a partir de este fragmento elocuente:

Paso revista al sueño: he recibido la visita de Tomatis en traje de montar, he vagado por la ciudad, he visto a Elisa y a mi madre, he llegado por fin a la casa de juego que era al mismo tiempo un prostíbulo. En lugar de fichas se jugaban pedacitos de carne cruda. De pronto, toda la sala se puso a temblar y me di cuenta de que estaba en un barco, en plena noche y en plena tormenta. Creo que he estado también en una carnicería: sí, una carnicería donde no vendían más que carne de caballo (29-30). 
Al recorrer estas líneas, el lector contacta de modo repentino con El limonero real (1974) y presencia un movimiento regresivo en la escritura: de lo "asado" en El limonero real, se regresa a lo "crudo" en la quinta novela de Saer. Sea lo que fuere, el valor lúdico de la carne en el sueño del Gato se asocia de modo chocante al malestar humano que circunda toda la novela. Aquí podemos apreciar el peso de la carne cruda como moneda, significante mortífero en la producción onírica del Gato: la expresión "carne cruda" remite en castellano a la palabra "fiambre" y a su sentido coloquial que es el de "persona muerta, sin vida" $(V O X)$. La carne cruda se torna luego en un significante indispensable a la entrada en el juego de azar y, al mismo tiempo, es la base alegorizada que permite la entrada en las realidades extraliterarias de la Argentina a partir de su anclaje onírico ${ }^{12}$.

En realidad, el orden monetario interesa en la novela por ser profundamente motivado y por ser el significante que permite la inmersión lúdica en el casinoprostíbulo. Tratemos de ver si esta moneda ("pedacitos de carne cruda") es cuestionable desde un ángulo a la vez azaroso y psicoanalítico. De hecho en este episodio figura el punto nodal de todos los juegos de alea. En Los juegos y los hombres, Caillois los define del siguiente modo: “[...] juegos

12 Por otra parte, a nivel intertextual, las líneas citadas hacen pensar en la carne como moneda en un gran clásico, The Merchant of Venice, si se nos ocurre recordar el peligro al que se exponía Shylock. Leamos a Shakespeare: [Shylock]: "O father Abram, what these Christians are, /Whoses own hard dealings teaches them suspect/ The thoughts of others!Pray you, tell me this;/ If he should break his day, what should I gain/ By the exaction of the forfeiture?/ A pound of man's flesh taken from a man/ Is not so estimable, profitable neither, /As flesh of muttons, beefs, or goats. I say/ To buy his favour, I extend this friendship:/If he will take it, so; if not, adieu;/And, for my love, I pray you wrong me not"(26).[...]/ [Portia]:"Tarry a little; here is something else./This bond doth give thee here no jot of blood;/The words expressly are 'a pound of flesh;'/Take then thy bond, take thou thy pound of flesh;/But, in the cutting it, if thou dost shed/One drop of Christian blood, thy lands and goods. Are, by the laws of Vencie, confiscate/Unto the state of Venice" (98-99).

El análisis llevado a cabo por Molina Foix es esclarecedor :[...] "Las metáforas monetarias se alternan, sin embargo, con las eróticas y las teológicas, en un tejido de signos en el que la pasión amorosa (la encubierta de Antonio por Bassanio, la de Bassanio y Porcia, mutuamente correspondida) tiene precio y regalo por encima de los sentimientos; el cuerpo humano se convierte en mercancía, sujeta como cualquier otra al rédito de un capital hecho carne; la religión sirve de fianza y de bancarrota. En esa Venecia económica que desaparece de la acción al acabar el acto cuatro, Shakespeare -conviene también subrayarlo-reparte equitativamente los rasgos de codicia y atroz aborrecimiento racial: los muestran los dos judíos, Shylock y Túbal, y, en igual medida el grupo de vitelloni cristianos que rodea al bondadoso Antonio" (Shakespeare 2005, 12-13). 
fundados [...] sobre una decisión que no depende del jugador, sobre la que no sabría tener la menor influencia y en los que no se trata por consiguiente de ganar mucho menos sobre un adversario que sobre el destino [...]" (56). Opinamos que el dinero entregado a las manos del alea en el casino se halla cargado de un sentido -a lo mejor críptico- que conviene interrogar más profundamente procurando explicitar las estrategias literarias de Saer a la hora de celebrar la reunión del azar y del psicoanálisis, en clave alegórica, en un barco-prostíbulo-casino. Para profundizar en estos temas, creemos de interés esclarecer lo que se esconde detrás del juego con la moneda en Saer.

Bien podríamos empezar por retomar la metáfora saussuriana de la pieza de moneda para entender la vía lúdica que emprende Saer para llegar a delatar lo arbitrario ${ }^{13}$ asociado con la dictadura. Es, pensamos, en este terreno donde tenemos que volver a pensar en el valor monetario del sueño, teniendo en cuenta que las metáforas monetarias son frecuentes en Saer y especialmente visibles en La pesquisa ${ }^{14}$. De hecho, el recurso a Saussure puede ser instructivo, de modo peculiar, esta cita que se encuentra en "El valor lingüístico considerado en su aspecto material":

Todos los valores convencionales presentan ese carácter de no confundirse con el elemento tangible que les sirve de soporte. Así no es el metal de una pieza de moneda que fija el valor de ésta; un

13 En Glosa, la arbitrariedad llega a asolar un relato que se halla vapuleado hasta la muerte por el autor. Dice J. Premat al respecto: “Las primeras líneas de la novela desmontan irónicamente la arbitrariedad que consiste en elegir un referente temporal cualquiera como punto de partida para la diégesis ficcional, proponiéndole luego al lector un rasgo esencial de delimitación de la instancia personaje: su nombre" (Premat, La dicha de Saturno... 74).

14 Señalamos unas pistas en la novela policiaca de Saer, La pesquisa (1994), para profundizar en estas reflexiones, por lo que esta novela comparte con Nadie nada nunca un juego acerca de la moneda y que esto posiblemente alude a lo arbitrario,; por lo demás se plasma por igual en el sueño de Morvan: "Un solo detalle en esa ciudad sombría le parecía absurdo, por no decir grotesco, y en el transcurso del sueño le inspiraba una indignación sarcástica, sin que su atrocidad implícita dejara de sentirse vagamente como una amenaza. Las efigies que adornaban los billetes de banco, en vez de ser retratos de personas ilustres, representaban monstruos de la mitología: Escila y Caribdis en los billetes más chicos, Gorgona en los medianos y Quimera en los más grandes. Los dibujos que las representaban en el interior de unos óvalos hechos de guirnaldas entrelazadas - como si quisiera rendírseles un homenaje delicado- estaban impresos con una gran precisión de detalles y Morvan, al hacer deslizar los billetes en su mano para contemplarlos, se preguntaba si tanta delicadeza con esos seres espantosos no indicaba que esos podrían ser los dioses que los habitantes de la ciudad iban a adorar" (31). 
escudo que vale nominalmente cinco francos solo contiene la mitad de esta suma en dinero; valdrá más o menos con tal o tal efigie, más o menos por debajo o por arriba de una frontera política. Esto es aún más verdadero para el significante lingüístico; en su esencia, no es fónico de ningún modo, es incorporal, constituido, no por su sustancia material, sino únicamente por las diferencias que separan su imagen acústica de todas las demás (164).

Toca esclarecer que lo fuerte en la representación de los sistemas semióticos en el sueño del Gato es que la arbitrariedad monetaria transpuesta en una casa de juego, dentro de un sueño, en un fondo inconscientemente freudiano, pueda leerse como una alegoría de la Argentina bajo el reino arbitrario de la tortura $^{15}$. Ni que decir que la arbitrariedad monetaria es justamente lo que permite la entrada en el azar del sueño, pero no se confunde con ella, dado que se halla "justificada" de modo mortífero en la carne cruda.

Para entender mejor las modalidades de unión entre el mundo del casino y el del sueño en Saer, cabe hacer hincapié no solamente en el orden monetario y el alto grado de arbitrariedad que se le suele asociar. En efecto, igualmente hay que ver cómo este asunto se plasma en el universo de juego. Ni que decir tiene que en los casinos el problema de la arbitrariedad se intensifica, la moneda juega con un orden diferente porque remite a otro sistema monetario que constituye otra manifestación de lo arbitrario. ¿Qué significa entonces la sustitución de la moneda clásica de los casinos, las "fichas", por los pedazos de carne cruda? La carne cruda se sustituye a las fichas de la misma manera que las fichas se sustituyen a la moneda, es decir, según la misma lógica arbitraria. Podemos adelantarnos a decir que, como en las distintas formas de dictadura, también es una cuestión de sustitución de un orden por otro según el sistema arcaico de la arbitrariedad del poder (Cyrulnik).

Considerándolo bien, la interpretación que proponemos parece coincidir con las tesis defendidas por Avelar en su análisis de la alegoría en los tiempos de

15 Igualmente podría ser instructiva una muestra de lingüística aplicada por parte de los dictadores argentinos dentro de una perspectiva contrastiva. De hecho, es curioso ver que los problemas asociados a la arbitrariedad del lenguaje preocuparon hasta a los dirigentes argentinos por su posible vínculo con el mal: "El almirante Emilio Massera rastrea el origen del mal en el hecho de que 'las palabras, infieles a su significado, perturbaron el raciocinio', produciéndose así la tan aborrecida "malversación del pensamiento"' (Avellaneda 17). Esta curiosa asociación entre el mal y las palabras tiene una base en la concepción de la mutabilidad del signo lingüístico considerada como peligrosa. 
mercado. De hecho, este especialista sostiene que: "La mercantilización niega la memoria porque la operación propia de toda nueva mercancía es reemplazar la mercancía anterior, enviarla al basurero de la historia. El mercado opera de acuerdo con una lógica sustitutiva y metafórica según la cual el pasado está siempre en vías de volverse obsoleto" (285). Según Avelar, la alegoría consiste en la resistencia al trabajo de duelo en la sociedad de mercado y sus investigaciones evocan una tarea importante para los escritores, que es la de "hablar otramente":

La alegoría es el tropo de lo imposible, ella necesariamente responde a una imposibilidad fundamental, un quiebre irrecuperable en la representación. Si una de nuestras premisas aquí es la derrota histórica que representan los regímenes militares ha implicado también una derrota para la escritura literaria, se impone la tarea de "hablar otramente" (allos-agoreuein) (316).

A partir de las tesis de Avelar, podemos apreciar mejor que a Saer le guste aplicar las lógicas al cuadrado, como buen heredero de Borges que es: para figurar la sustitución, el escritor santafesino elige un "desplazamiento dinerario". De hecho, es la moneda misma -agente de la sustitución por excelencia, en su cualidad de atributo del mercado-que está sustituida y metaforizada para representar el orden nuevo. Y es preciso no olvidarse, siguiendo a Cyrulnik en Los alimentos afectivos que en los tiempos de dictadura: "el universo del signo crea un nuevo orden mental en el que todas las violencias son posibles porque todas las libertades son posibles: la de destruir una regla para proponer otra, la de destruir a quien quebrantase esta regla, la de destruir un grupo a nombre de la idea que se hace de él o de la amenaza que representa" (148). Con tal aseveración se entiende mejor el grado de violencia que se postula como fundamental en la dictadura y que tiene que ver con la arbitrariedad del universo del signo, un problema que ve su relevancia desmultiplicarse al contactar con el universo del casino ya hiperbólico de por sí. Como constatamos, para "alegorizar la dictadura" (Corbatta, Narrativas de la guerra sucia en Argentina 77), Saer juega con el significante mortífero de la carne cruda en una base lúdica que suscita muchas preguntas.

Mirándolo bien, en este episodio, la carne cruda refleja la muerte omnipresente en la novela y se parece al "residuo" que materializa la imposibilidad de una sustitución sin resto en una base marcadamente mercantil. La muerte sigue contaminando al presente y la regresión hacia el valor de uso en un casino -por excelencia, el lugar de derroche del valor de cambio (disimulado en las 
fichas eufemísticas)- resulta, a fin de cuentas, significativa. Esto nos aparece todavía más llamativo si se postula que el regreso del azar en este lugar supuestamente desprovisto de azar que es el sueño después del psicoanálisis, es una alegorización de este residuo tenso, todavía invisible, perdido entre los anagramas casual-causal. El juego le sirve a Saer para hacernos entender el grado de arbitrariedad del poder en las épocas en las que el caos más se hace sentir y nos enseña el movimiento de regresión de la especie humana en tiempos de turbaciones políticas.

Para entender de modo más preciso en qué medida el sueño lúdico del Gato testimonia una verdadera involución de la especie humana en la regresión al valor de uso asociada a la alegorización de la dictadura en Nadie nada nunca, decidimos acudir a La psychanalyse de l'argent de Borneman. Las investigaciones de Borneman se ubican en el cruce de las tesis freudianas y marxistas, tesis que siempre suscitaron cierta admiración por parte de Saer que veía en ellas un reservorio de materia primeriza inagotable para sus ficciones ${ }^{16}$. En su ensayo, Borneman explica que existe un desplazamiento desde el valor de uso hacia el valor de cambio, lo cual es, según él, sintomático del proceso de represión de lo concreto, de lo útil y de lo sensible por lo abstracto y lo inútil (420-423). En realidad, Borneman ve en el paso del valor de uso al valor de cambio un proceso de represión. Para Borneman, la transformación cotidiana de los valores tangibles en otros intangibles habría hecho evolucionar a la especie humana, por lo menos en el capitalismo de hoy, a nivel de su vida espiritual. La represión, según Borneman, se sitúa a nivel de las necesidades naturales y sensibles de los seres humanos. Resulta de todo esto, entre otras consecuencias, una carrera hacia el dinero. Este cambio, según él, tiene su corolario en un proceso psíquico de adaptación

16 A este respecto, el análisis que Saer hace del valor de cambio en el arte se relaciona con las tesis de Borneman. En sus Trabajos, Saer critica generosamente el posmodernismo y se le ocurre recurrir al mismo léxico económico, como "valor de cambio" y "valor de uso": "Su [el posmodernismo] oposición a las vanguardias no es artística, sino supuestamente ética, política, cultural: a la tiranía irrazonable de las vanguardias, opone el democratismo posmoderno. En su chirle relativismo, los contrarios, si no siempre se reconcilian, existen en un plano de igualdad, de tal manera que, en su opinión, Isabel Allende y Juan Carlos Onetti por ejemplo, son igualmente novelistas, y dentro de la lógica democratista que hace del público la instancia decisiva del proceso creador, la supremacía le corresponde al más votado o sea, en el crudo lenguaje economicista que prevalece hoy en día, al más vendido. La prioridad en arte del valor de cambio sobre el valor de uso define bastante claramente la concepción posmoderna" (10-11). 
que se actualiza en los mecanismos de defensa freudianos; y entre estos, la represión, cuyo carácter pertinente y fundador a la hora de considerar los fenómenos con inteligencia es resaltado en su estudio. Este ensayista, al igual que Borges en "El zahir" (El Aleph) aseverando "El dinero es abstracto, repetí, el dinero es tiempo futuro" (Obras completas 591), pero con otras intenciones, califica el dinero de "abstracto" y de fenómeno sin límites, como bien se puede apreciar en esta cita:

Pero el motor de este proceso psíquico es siempre y por todas partes el dinero, que es tanto abstracto como sin mesura: sin mesura porque no satisface ninguna necesidad concreta, sensible y se sustrae así a la limitación natural de todas las demás necesidades. El que ha comido está saciado. El que ha bebido lo suficiente ya no tiene sed. La satisfacción en asuntos de deseo sexual igualmente conoce límites corporales. Solo las ganas de dinero son ilimitadas (422).

Más adelante, Borneman se apoya en la leyenda de Midas para mostrar el carácter destructor e inútil del dinero. En el marco de este estudio nos limitaremos a mencionar que en Nadie nada nunca se observa un movimiento inverso al que explica Borneman. En efecto, asistimos a una etapa de regresión importante, ya que antes la moneda tenía una utilidad directa y no "sufría" tanta arbitrariedad como hoy, si nos ponemos a pensar en el mecanismo del trueque evocado en las alturas primerizas de la obra de Saer (Responso). Pensamos que la asociación entre regresión y arbitrariedad va estableciéndose por vías crípticas: el vuelco en el mal de la época se traslada a los sistemas de signos y es el mismo terror que rige el curso del juego. Por lo tanto, la presencia de dinero en Saer es interpretable a partir de su búsqueda en el terreno lúdico pero también a partir de la regresión de la especie humana en tiempos de dictadura. En efecto, cuando el telón de fondo histórico apunta a la guerra sucia, observamos que el "siempre más" al que alude Borneman desemboca en la esfera de la violencia física y sexual. Es aquí donde tenemos que precisar que el "valor literario" del dinero en Saer -interpretable, como intentamos enseñarlo, en la reunión de los horizontes psicoanalítico y azaroso- reenvía no menos significativamente a la lectura de Sade (Corbatta, Narrativas de la guerra sucia en Argentina 77).

Si todo el ciclo literario de Saer está caracterizado por una violencia sin par, hace falta recordar que esta veta de su obra alcanza una dimensión álgida en Nadie nada nunca. Es altamente revelador que el dinero se ofrezca como la verdadera base sobre la que se despliegan tanto las pulsiones de juego 
como las pulsiones de muerte. Para apreciar mejor la presencia de dinero en esta novela de Saer, resulta instructivo adentrarnos en la lógica del "siempre más" que tanto parece imperar en el casino, en la tortura de los caballos $\mathrm{y}$, más generalmente, en todas las muestras de sadismo en la obra. No en vano la investigación sobre el dinero llevada a cabo por Borneman otorga un papel tan importante al sadismo y al masoquismo. Llama la atención cierto paralelismo: se podría acercar la visión de la sexualidad tal y como se practica en Nadie nada nunca y la insatisfacción delatada por Borneman en asuntos económicos. Puede que se desemboque por esta vía también en la patología obsesiva de un matador múltiple, sea en Nadie nada nunca o en La pesquisa. De hecho, Nadie nada nunca plantea una superación de lo natural que se puede observar en el hombre involucrado en una orgía, por ejemplo, o cuando se asesina por una razón que se desconoce. Estas líneas constituyen una muestra elocuente de la recuperación de Sade en la novela:

El caballero, que al final debía terminar exaltando los sentimientos puros y confesando que se prestaba a las manipulaciones de sus amigos por simple simpatía y buena educación, mostrando de ese modo que se había mantenido todo el tiempo un poco aparte del grupo, no podía plantearse el problema tal como saltaba a la vista: en el elogio gradual que iba de la cópula al asesinato, pasando por la masturbación, la succión, la sodomía, la coprofagía, el masoquismo y el sadismo, su hermana la señora de San Angel y el bufarrón Dolmancé, que eran los teóricos entusiastas de esas actividades, confesaban de un modo implícito su fracaso, ya que al último estado de voluptuosidad, el asesinato, se llegaba justamente a causa de la imposibilidad de obtener un goce pleno en los estadios inferiores (185). [...] Se llegaba al asesinato por desesperación y sobre todo, para salir de la esfera de sexualidad que, como lo probaban las diferentes prácticas, no daba ninguna satisfacción (187).

Como podemos ver, en Nadie nada nunca estamos inmersos en el "siempre más" monetario - está el mundo del casino para reflejarlo- pero esta lógica adquiere una fuerza orgiaca que descansa en la lectura de Sade y que sitúa el asesinato como punto culminante de la esfera sexual. Así las cosas, el dinero en Saer sería igualmente analizable a partir de su papel en la literatura sádica en una estrecha relación con la cuestión del abuso del poder característico de la dictadura argentina.

Ahondando en la recurrencia del motivo del dinero en Saer nos damos cuenta de que tiene que ver con el fondo sadeano de su obra. Jitrik en "José 
Donoso: Parodia y Pornografía" comenta esta asociación que no siempre salta a la vista y opinamos que sus observaciones son igualmente válidas para Nadie nada nunca:

Este elemento, el del dinero, suele estar en el paradigma de la literatura porno-erótica en un segundo plano tan distante y vago que, por contraste, produce una atmósfera de irrealidad, de sueño; en Sade su acción es de sostén de una mecánica más evidente, o en primer plano, de lucha por el poder o por la dominación. El sistema capitalista se hace presente en toda su crudeza, el poder está mezclado con el dinero $\mathrm{y}$, por lo tanto, quien amenaza su posesión constituye un riesgo: por ellos es, a su turno, amenazado y por fin desaparecido (209).

Es cierto que poder, dinero y sexo es un tríptico que se diseña en la narrativa de Saer y que se sedimenta en la forma del episodio onírico y aleatorio del casino, lo cual motiva la adscripción al intertexto sadeano. El vocabulario empleado por Saer en Nadie nada nunca es revelador y traiciona cierta familiaridad con el lenguaje vigente en la prostitución ${ }^{17}$. En este terreno macabro, la prostitución es especialmente clave en Nadie nada nunca, una vez que la situamos en la encrucijada del sueño y del juego. Mirándolo bien, la circulación del dinero constituye un punto crucial en el sueño del Gato. Es curioso notar que la misma asociación hallada en Saer entre la prostitución y el azar parece provenir del fondo sadeano. Leamos a Mme. de Saint-Ange, en un fragmento de La filosofía en el tocador de Sade, intertexto mayor de Nadie nada nunca:

Señorita de Saint-Ange.-Sí, he estado allí como una puta, he satisfecho durante una semana entera los fantasmas de varios libertinos y he visto allí gustos bien singulares; por un semejante principio de libertinaje,

17 Este rasgo acercaría Saer a Arlt en Los siete locos. Al respecto, un artículo de $E l$ País presenta el balance de la prostitución en el mundo hispánico. "El nuevo mercado ha tenido éxito. La demanda ha aumentado y el negocio se ha convertido en una mina de oro que necesita renovar la mercancía constantemente. Para eso los mercaderes han creado redes perfectamente diseñadas para abastecer nuestras calles, polígonos, pisos y clubes de carretera. El mismo sistema que se emplea para importar tomates: un recolector, un distribuidor, un transportista y un vendedor. En las escuchas policiales los agentes suelen oír frases como 'tengo tres kilos de carne' o 'he traído unos terneritos'. Los terneros son mujeres de entre 18 y 25 años, las que se pueden colocar en cualquier sitio" (Ceberio Belaza Álvaro de Cózar 2009). 
como la famosa Emperatriz Teodora, mujer de Justiniano, me he dedicado a la prostitución en las calles...en los paseos públicos, y he jugado a la lotería el dinero de esas prostituciones (76).

Es aquí donde se ve bien que la dimensión carnal rezuma de sentido en Nadie nada nunca y que explota el fondo sadeano y sádico en la encrucijada de los juegos que necesitan un prepago, esto es, los vértigos del ilinx (juegos de vértigo según Caillois 71) sexual o el alea (Caillois 57) de la casa de juego. Considerándolo bien, Nadie nada nunca consta de ciertos ecos de las tesis propugnadas por Jitrik o Reati en Nombrar lo innombrable, por lo que la recuperación de Sade parece obedecer a apuestas estrechamente vinculadas con el dinero y la dictadura militar y se ven de modo más nítido en el sueño del Gato.

En este lugar final del análisis, quisiéramos volver sobre un punto crucial para entender el sentido mortífero de la combinación azar-psicoanálisis en Nadie nada nunca. Si se acepta ver que en los tormentos del alea, uno juega para volver a experimentar las sensaciones del juego en un estado precedente, luego, la esfera sexual tal y como se declina en Nadie nada nunca, se puede explicar mediante el mismo resorte y ahí estriba el reciclaje de Sade en tiempos de dictadura. Se llega de modo sádico al asesinato como colmo de la sexualidad (185), para volver a buscar y a experimentar sensaciones más fuertes, según la lógica del "siempre más". Este mecanismo se incorpora en el plan de una intriga que no se llega a solucionar y de una escritura que no deja de regresar sobre sí misma como si no pudiese avanzar más. Esta tendencia simboliza, claro está, lo real argentino de aquellos años de dictadura y se fundamenta en una poética que participa en el trastrocamiento de las reglas del juego literario urdido por el Nouveau roman.

La descodificación que emprendimos intentó alumbrar el juego creativo de Saer para figurar la regresión de la humanidad en lugares de prostitución y de juego enmarcados por la ilusión, según la etimología illudere. El marco onírico del casino-prostíbulo parece apuntar a un cuadrado de doble entrada ilusoria que tendría en abscisa el alea y en ordenada el psicoanálisis y que presenciaría el sinfín de variaciones permitidas entre los modos del "como si" (Schaeffer 325) propio del juego y del "igual que"(Freud 360) característico del sueño. En este ámbito, la moneda llega a ser un significante clave e intentamos resaltar su valor peculiar tanto a nivel psicoanalítico como a nivel de su utilización en el marco del azar. 
Quisiéramos meditar ahora sobre el lugar del sueño en la novela de Saer, citando a Piglia en su análisis de la ficción en tiempos dictatoriales:

La ficción aparece como antagónica con un uso político del lenguaje. La eficacia está ligada a la verdad, con todas sus marcas: responsabilidad, necesidad, seriedad, la moral de los hechos, el peso de lo real. La ficción se asocia con el ocio, la gratuidad, el derroche de sentido, lo que no se puede enseñar; se asocia con el exceso, con el azar, con las mentiras de la imaginación como las llama Sarmiento. La ficción aparece como una práctica femenina, una práctica, digamos mejor, antipolítica $(1993,101)$.

Como leemos, durante la dictadura militar, el mero hecho de escribir una novela conllevaba cierta carga de subversión. ¿Qué decir del sueño entonces? Es muy llamativo el que en una época que censuró todo, la novela de Saer otorgue al sueño -único lugar que escapa a la censura por hacerla explotarun papel narrativo de mise en abyme que alegoriza la represión militar en el plan de una regresión del sistema semiótico del dinero. Al haber sucedido lo "innombrable" (Reati) en la historia argentina coetánea con el texto, es lógico que el autor, en términos de Avelar "habl[e] otramente" mediante este sueño. Come tuvimos la ocasión de apreciarlo, en el marco onírico de Nadie nada nunca, las realidades de la carne y del caballo, -huellas estereotipadas de la argentinidad de la obra- van a "revelarse otras". Parece que conforme con los avances del horror en la historia argentina se agudizan las prácticas de los juegos en la poética de $\operatorname{Saer}^{18}$. El sueño emblemático del Gato constituye por cierto una mise en abyme del inconsciente del Gato, por lo que también evoca sus preocupaciones para con los caballos, su virilidad y Elisa. Sin embargo, cabe mencionar que propone al tiempo otra mise en abyme -más rebuscada, pensamos- de la manera con la cual la novela alegoriza lo arbitrario dictatorial al diseñar una regresión en el uso de los sistemas de signos en la casa de juego instrumentalizando las colusiones de intereses azarosos y psicoanalíticos.

18 Dice Reati al respecto: 'La novelística que representa la 'guerra sucia' puede actuar a modo de revulsivo, como una conciencia que violenta la sociedad al obligarla a mirarse en una imagen deformante pero paradójicamente de atroz fidelidad. A través de su búsqueda de una lectura simbólica de la violencia que no sea maniquea ni autoritaria, la novela argentina del período 1975-1985 emprende lo que tal vez sea el intento más serio de autocuestionamiento en la sociedad argentina" (241). 
Sin dar lugar a dudas, uno de los puntos de interés en la literatura de Saer es que su proyecto se llevó a cabo a partir de la tensión fructífera entre el mundo del juego y las reescrituras del psicoanálisis freudiano. Este trabajo intentó cumplir con el objetivo de desarrollar estos acercamientos que se dan con especial fortuna en Nadie nada nunca explorando una vía interpretativa que tendió a otorgar un sentido a una co-presencia llamativa del azar del psicoanálisis. Nuestras reflexiones buscaron esclarecer el sentido de este encuentro (¿surrealista?) mostrando las conexiones crípticas que remandaban a las realidades extraliterarias. Como pudimos ver, la escritura de Saer incorpora mecanismos azarosos en una postura que da la impresión de ser algo paródica con respecto al psicoanálisis, pero que no niega su fecundidad en el plan de la elaboración de una grandísima obra literaria cíclica.

\section{BIBLIOGRAFÍA}

Arlt, Roberto. Los siete locos. 1929. Madrid: Cátedra, 2005.

Avelar, Idelber. Alegorías de la derrota: la ficción postdictatorial y el trabajo del duelo. Santiago de Chile: Editorial Cuarto Propio, 2000.

Avellaneda, Andrés, “Argentina militar: los discursos del silencio”. En Kohut, Karl y Pagni, Andrea. Literatura argentina hoy. De la dictadura a la democracia. Frankfurt am Main: Vervurt, 1993.

Baudrillard, Jean. Les stratégies fatales. Paris: Grasset, 1983.

Borges, Jorge Luis. Euvres complètes. Introduction, Chronologie et notes par Bernès, JeanPierre. t.1 y 2, Paris: La Pléiade, 2010. Obras completas. Buenos Aires: Emecé Editores, 1974. Libro de sueños. Madrid: Alianza editorial, 2008.

Borneman, Ernest. Psychanalyse de l'argent. Une recherche critique sur les théories psychanalytiques de l'argent. Trad. Daniel Guérineau. Paris: Presses universitaires de France, 1978.

Caillois, Roger. Les jeux et les hommes. Le masque et le vertige. Paris: Gallimard, 1967.

Ceberio Belaza Álvaro de Cózar, Mónica. "Explotación sexual en España 1". El país, Domingo 17 de mayo de 2009.

Corbatta, Jorgelina. Narrativas de la guerra sucia en Argentina. Buenos Aires: Corregidor, 1999. Juan José Saer, Arte poética y práctica literaria. Buenos Aires: Corregidor, 2005.

Cyrulnik, Boris. Les nourritures affectives. Paris: Odile Jacob, 2000.

Dalmaroni, Miguel Ángel y M. Merbilhaá, Margarita. "Un azar convertido en don. Juan José Saer y el relato de la percepción”. En Jitrik, Noé. Historia crítica de la literatura argentina. La narración gana la partida, v. 11, Buenos Aires: Emecé Editores, 2000: 321-343. 
Diccionario de la Real Academia Española. "Real Academia Española”. http://rae.es/recursos/ diccionarios/draehttp://buscon.rae.es/draeI/ consultado el 7 de noviembre de 2013.

Freud, Sigmund. L'interprétation du rêve. 1900. Trad. Jean-Pierre Lefebvre. Paris: Seuil, 2010.

Genette, Gérard. Figures III. Paris: Seuil, 1972.

Giordano, Alberto. "El efecto de irreal". Discusiones 1 (1989): 27-36.

Huizinga, Johan. Homo ludens. Essai sur la fonction sociale du jeu. 1938. Trad. Cécile Seresia. Paris: Gallimard, 1951.

Iglesia, Cristina. La violencia del azar. Ensayo sobre literatura argentina. Buenos Aires: Tierra firme, 2003.

Jitrik, Noé. “José Donoso: "Parodia y Pornografía”. Suspender toda certeza. Selección y prólogo por Gonzalo Aguilar y Gustavo Lespada. Buenos Aires: editorial Biblos, 1997.

Morin, Edgar. La rumeur d'Orléans. Paris: Seuil, 1969.

Onetti, Juan Carlos. El astillero. 1961. Madrid: Punto de lectura, 2008.

Panesi, Jorge. “Cicatrices de Juan José Saer: el peligroso juego de la literatura”. Pie de página 2 (1983): 28-29.

Piglia, Ricardo. "El lugar de Saer". El lugar de Piglia. Crítica sin ficción. Ed. Jorge Carrión. Barcelona: Editorial Candaya, 2008.

"Ficción y política en la literatura argentina". En Kohut, Karl y Pagni, Andrea. Literatura argentina hoy. De la dictadura a la democracia. Frankfurt am Main: Vervurt, 1993.

Premat, Julio. La dicha de Saturno. Escritura y melancolía en la obra de Juan José Saer. Rosario: Beatriz Viterbo, 2002.

"Saer, nota y sinfonía". Paris: Université de Paris 8 encontrado en dialnet.unirioja. es/servlet/fichero_articulo? codigo...0 y consultado el 05 de marzo de 2010.

Puig, Manuel. Pubis angelical. Barcelona: Seix Barral, 1998.

El beso de la mujer araña. Buenos Aires: Seix Barral, 1976.

Ricardou, Jean. Le nouveau roman. Paris: Seuil, 1973.

Reati, Fernando Oscar. Nombrar lo innombrable. Violencia política y novela argentina: $1975-$ 1985. Buenos Aires: Editorial Legasa, 1992.

Saer, Juan José. La vuelta completa. 1966. Buenos Aires: Seix Barral, 2001.

Responso. 1964. Buenos Aires: Seix Barral, 1998.

Cicatrices. 1969. Buenos Aires: Seix Barral, 1994.

El limonero real. 1974. Buenos Aires: Seix Barral, 2002.

Nadie nada nunca. 1980. Buenos Aires: Seix Barral, 1995.

Glosa. 1986. Buenos Aires: Seix Barral, 1995.

La pesquisa. Buenos Aires: Seix Barral, 1994.

Cuentos completos. Buenos Aires: Seix Barral, 2001.

La grande. Buenos Aires: Seix Barral, 2005.

Trabajos. Buenos Aires: Seix Barral, 2005.

de Sade, Donatien Alphonse François. La philosophie dans le boudoir. 1795. Paris: Poche, 1972. 
Sarlo, Beatriz. "Narrar la percepción”. Punto de vista 10 (1980): 34-37.

de Saussure, Ferdinand. Cours de linguistique générale. 1916. Edition critique préparée par

T. de Mauro. Paris: Payothèque, 1972.

Schaeffer, Jean-Marie. Pourquoi la fiction? Paris: Seuil, 1999.

Shakespeare, William.The Merchant of Venice. 1623. Paris: Librairie Hachette, 1925.

El mercader de Venecia. Prólogo a cargo de Vicente Molina Foix. Trad. Luis Astrana

Marín. Madrid: Alianza Editorial, 2005.

Trésor de la langue française informatisé.

“Atilf.atilf.fr" http://atilf.atilf.fr/dendien/scripts/tlfiv5/advanced.exe?8;s=3108399000 y consultado el 7 de noviembre de 2013.

VOX. Diccionario de uso del español de América y España. Barcelona: SPES, 2002.

Winnicott, Donald Woods. Jeu et réalité. L'espace potentiel. 1971. Trad. Claude Monod.

Paris: Gallimard, 1975. 